\title{
Fortalecimiento de la comprensión lectora a través de las artes plásticas y escénicas*
}

\author{
Strengthening of reading comprehension through \\ the visual and performing arts
}

\author{
Pablo Andrés Jaimes Roa ${ }^{1}$
}

Para citar este artículo: Jaimes, P. A. (2019). Fortalecimien-

to de la comprensión lectora a través de las artes plásticas y escénicas. Infancias Imágenes, 19(2), 49-64s

\section{Resumen}

El presente artículo se basa en una investigación desarrollada por dos docentes de Lengua Castellana en grados diferentes de la educación básica desde el enfoque cualitativo. Se usó la metodología de investigación-acción en cuatro fases cíclicas: planeación, acción, observación y reflexión. Se presentan los instrumentos de recolección de datos que se usaron en la investigación como la encuesta, el diario pedagógico y una bitácora de metacognición; haciendo énfasis en este último pues permitió a los estudiantes apropiarse del proceso cognitivo y reflexionar sobre su aprendizaje durante la intervención pedagógica. Finalmente, se expone cómo un método de enseñanza basado en la mediación de diferentes manifestaciones de las artes plásticas y escénicas fortalece la comprensión lectora de los estudiantes.

Palabras clave: lectura, comprensión, método de enseñanza, arte, redacción, expresión oral, expresión corporal, comunicación.
Recibido: 04-08-2019 - Aceptado: 24-05-2020

\begin{abstract}
This article is based on an investigation developed by two teachers of the Spanish language, Spanish Language, in different degrees of basic education from the qualitative approach using. The research methodology-action was used in four cyclical phases: planning, action, observation and reflection. The data collection instruments that were used in the research are presented, such as the survey, the pedagogical diary and a metacognition log; emphasizing the latter, since it allowed students to appropriate the cognitive process and reflect on their learning during the pedagogical intervention. Finally, it is exposed how a teaching method based on the mediation of different manifestations of the plastic and performing arts strengthens students' reading comprehension.
\end{abstract}

Keywords: reading, comprehension, teaching method, art, writing (composition), oral expression, movement education, communication.

Artículo derivado del trabajo "Fortalecimiento de la comprensión lectora a través de una secuencia didáctica mediada por el arte en estudiantes de tercero y séptimo grado del Instituto Gabriel García Márquez del municipio de Floridablanca". Investigación que inició en el año 2017 y finalizó en el año 2018. Financiada por el Ministerio de Educación Nacional a través del fondo de becas para la excelencia docente y avalada por la Universidad Autónoma de Bucaramanga (Colombia).

1 Magister en Educación, licenciado en Lengua Castellana y Normalista superior. Docente vinculado a la Secretaría de Educación del municipio de Floridablanca, Santander. Correo electrónico: pabloandres87@hotmail.com. Orcid: https://orcid.org/0000-0002-6444-8811 


\section{Introducción}

La comprensión lectora es planteada en la actualidad como una de las principales habilidades que toda persona debe desarrollar para integrarse social, económica y culturalmente a la sociedad. Al respecto, el Centro Regional para el Fomento del Libro en América Latina y el Caribe (Cerlalc) afirma: "La lectura y la escritura son condiciones para que todas las personas puedan alcanzar un nivel básico de educación y continuar su proceso de aprendizaje durante toda la vida" (2004, p. 12).

Parece claro que la apropiación de la habilidad o competencia lectora se convierte en el principal objetivo educativo en las aulas de clase para construir conocimiento y desarrollar nuevas capacidades. Sobre esto, el Instituto Gabriel García Márquez del municipio de Floridablanca (Santander, Colombia) estableció como prioridad para la comunidad educativa mejorar el nivel de comprensión lectora de los estudiantes de básica primaria, básica secundaria y media. Para lograrlo la institución diseñó todo el currículo desde el enfoque constructivista y, a partir de allí, optó por un modelo pedagógico denominado "Enseñanza para la comprensión", desde el cual se orienta la elaboración de los planes de área y de clase teniendo en cuenta el componente básico denominado: elementos y dimensiones de la comprensión. En ese mismo sentido, en la institución se estableció la reestructuración de las prácticas educativas, de tal modo que propendan por las prácticas significativas de lectura y busquen desarrollar habilidades de pensamiento; es decir, construir aprendizajes significativos.

Las prácticas significativas de lectura y escritura que se realizan en el espacio escolar posibilitan el acceso al conocimiento, favorecen el desarrollo del pensamiento crítico y reflexivo y enriquecen la capacidad creativa, estética y simbólica de los niños. El logro de este objetivo contribuye a mejorar la calidad del aprendizaje. (Cerlalc, 2004, p. 22)

Es evidente, entonces, que la lectura debe ocupar un lugar privilegiado en la escuela y que, a su vez, se deben promover las prácticas significativas de la misma en el aula de clases. De allí que el objetivo de la investigación se centrase en fortalecer la comprensión lectora a través de una mediación que lograra ser significativa para los estudiantes. Como consecuencia los docentes indagaron en los intereses de los estudiantes para consolidar una propuesta de intervención pedagógica. Producto de ello, se logró establecer que los intereses de los estudiantes eran muy diversos, pero que existía un eje transversal en todas sus actividades favoritas y fue así que se logró identificar el arte como mediador en el proceso educativo. En este punto el uso del arte se convierte en el pilar de la propuesta de investigación dado que en este recae la mediación y acercamiento del estudiante hacia la lectura.

Las artes, la literatura, las artes visuales, la música, la danza, el teatro, son los medios más poderosos de que dispone nuestra cultura para dar intensidad a las particularidades de la vida. De esta forma las artes acrecientan el conocimiento. (Arnheim, 2015, p.18)

El uso del arte en el contexto escolar no solo está permitido, sino que resulta fundamental ponerlo en marcha por convertirse en un puente para desarrollar el pensamiento creativo de los estudiantes. De igual manera, el arte permite a los estudiantes encontrar modos de expresión únicos e infinitos en sus significados.

El principio sobre el que puede establecerse un rango de superioridad en la expresión artística es el proceso mental de abstracción, hasta llegar así a la sublimación de la capacidad creativa, al principio de lo mejor como lo más original y novedoso. (Read, 1975, p. 44)

De este modo, el objetivo de la investigación desarrollada fue fortalecer la comprensión lectora a través de una secuencia didáctica mediada por el arte, estructurada bajo el enfoque constructivista y en el modelo pedagógico de enseñanza para la comprensión. En este mismo orden y dirección, la secuencia se ejecutó en 12 actividades que desarrollaron las siguientes manifestaciones artísticas:

En síntesis, este artículo expone las prácticas significativas de lectura a través de estrategias mediadas por el arte, ajustándose al contexto del 
establecimiento educativo, en el marco de su proyecto educativo institucional a fin de fortalecer la comprensión lectora en los estudiantes del grado tercero y séptimo.

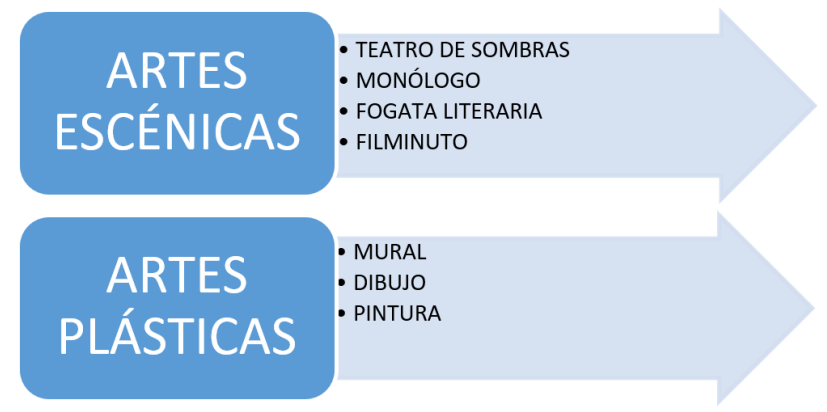

Figura 1. Manifestaciones artísticas.

Fuente: elaboración propia.

\section{Metodología}

Al iniciar el proceso de investigación los objetivos e intereses giraban en torno a la pregunta de investigación: ¿de qué manera fortalecer la comprensión lectora en estudiantes de tercero y séptimo grado del Instituto Gabriel García Márquez del municipio de Floridablanca (Santander, Colombia)? Se planteó, entonces, una investigación con un enfoque cualitativo, puesto que sus características exigen que desde el inicio se tenga claro el tema a ser investigado, la problemática objeto de estudio y el campo de investigación; así como delimitar bien el papel del investigador. A propósito, Ruiz afirma que: "Los métodos cualitativos son los que enfatizan conocer la realidad desde una perspectiva de incidir, de captar el significado particular que a cada hecho atribuye su propio protagonista, y de contemplar estos elementos como piezas de un conjunto sistemático" (2012, p. 17).

En este orden de ideas, el maestro investigador debe tener la habilidad de experimentar las cualidades de su entorno. Esto se entiende como aquellas percepciones de la realidad, que en el caso específico de esta investigación fue la realidad del aula de clase. Además, se consideró al aula de clase no como el espacio físico sino todo espacio donde se realizó construcción significativa en el que se involucran todos los componentes pedagógicos y didácticos de la acción educativa.
Dentro de los enfoques cualitativos, los investigadores optaron por la investigación-acción (IA) dado que, según sus características, basan las acciones del investigador en un proceso cíclico entre observación, acción y reflexión. Al respecto, Elliot (2010) alude la característica cíclica de la IA entre: diagnóstico, decisión, respuesta, evaluación y deliberación.

Adicionalmente, Latorre menciona que "Por lo general, los ciclos de investigación- acción se transforman en nuevos ciclos de modo que la investigación en sí puede verse como un ciclo de ciclos o como una espiral de espirales que tiene el potencial de continuar indefinidamente" (2003, p. 39).

La experiencia significó para los investigadores un constante ejercicio autorreflexivo, pues la comprensión lectora es un proceso interactivo en el cual necesariamente se debe involucrar al sujeto investigado.

La investigación se basó en las fases plateadas por Kemmis (citado en Latorre, 2003), para desarrollar la IA: plan de acción, acción, observación y reflexión. Como resultado se establecieron las siguientes fases que guiaron el desarrollo.

\section{Fase de planeación}

En esta primera fase se partió de una idea o identificación del problema, producto de la observación directa de los docentes con el grupo objeto de estudio. Seguidamente, se realizó un diagnóstico que permitió reconocer con mayor profundidad la problemática a intervenir y así lograr dar una explicación de la misma. Finalmente, como producto de la reflexión de la situación problema y del análisis de posibles soluciones, se eligió organizar las actividades en una secuencia didáctica mediada por las artes plásticas y escénicas para posibilitar el ordenamiento de los contenidos propios del área de Lengua Castellana, junto con las manifestaciones artísticas, en específico el teatro de sombras, el monólogo, la fogata literaria, el filminuto, el mural, el dibujo y la pintura.

\section{Fase de acción}

En esta se puso en funcionamiento la secuencia didáctica mediada por las artes plásticas y escénicas en los estudiantes objeto de estudio. Fue desarroIlada siguiendo un cronograma de actividades previamente establecido. 


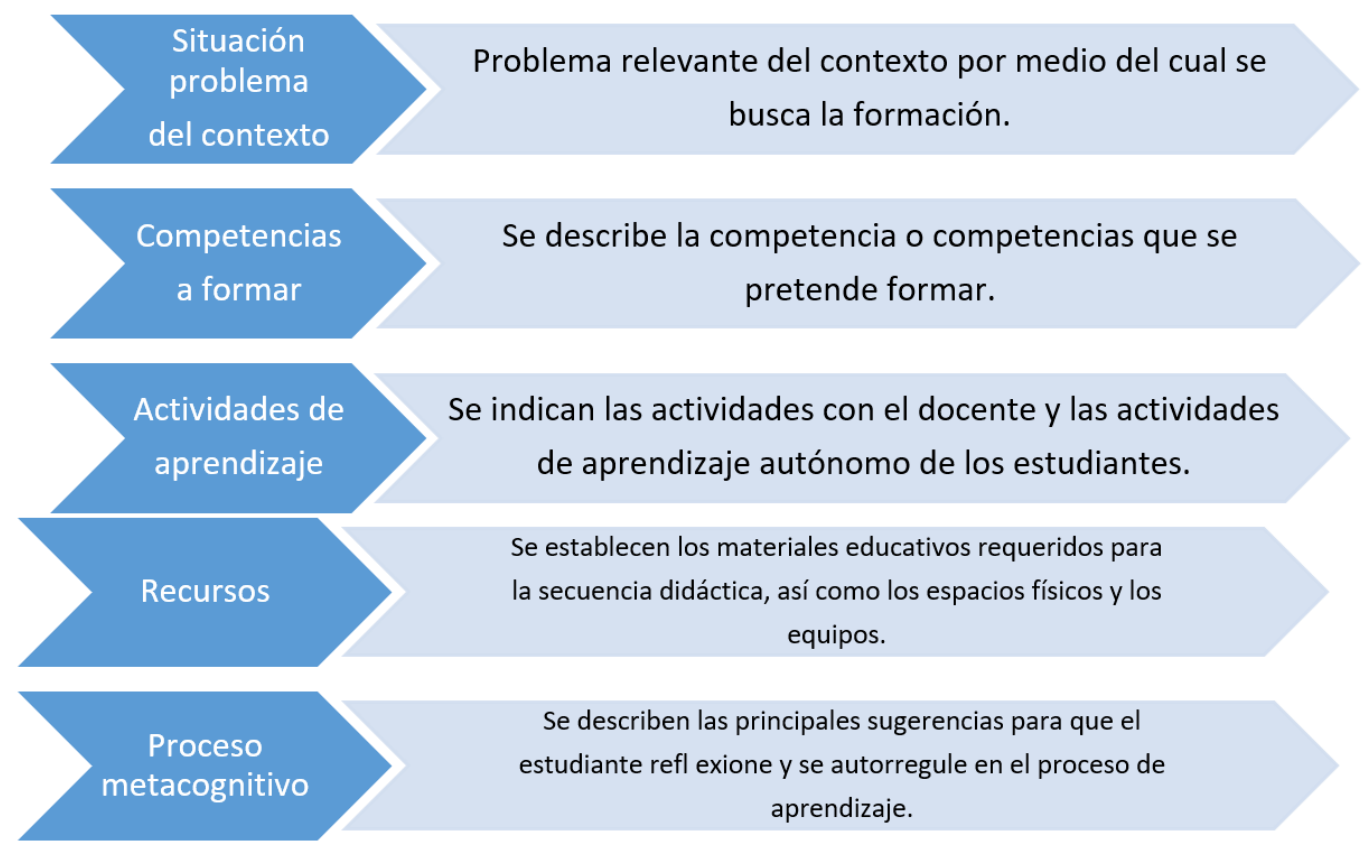

Figura 2. Principales componentes de la secuencia didáctica.

Fuente: Tobón et al. (2010, p. 22).

La secuencia didáctica fue organizada teniendo en cuenta elementos del enfoque constructivista y del modelo pedagógico institucional de enseñanza para la comprensión. Así mismo, se tomaron algunos elementos aportados por Tobón et al. (2010):

La secuencia didáctica fue guiada por tres fases secuenciales: exploración, estructuración y transferencia.

En la fase 1 (exploración) los estudiantes indagaron sobre la estructura narrativa de un texto mítico: inicio, desarrollo y desenlace. Así mismo, reconocieron características propias de los mitos, tales como su naturaleza fantástica. Finalmente, a través del arte, del teatro de sombras (primaria) y de monólogos (bachillerato), los estudiantes exploraron la magia artística de la tradición oral.

En la fase 2 (estructuración) los estudiantes continuaron explorando la estructura de un texto narrativo por medio del reconocimiento de leyendas. Los estudiantes reconocieron elementos de la tradición oral y reconstruyeron los textos usando la técnica artística de pintura con tizas sobre asfalto. Finalmente, en esta etapa los estudiantes investigaron sobre aspectos de sus vidas y realizaron entrevistas a sus compañeros.

En la fase 3 (transferencia) los estudiantes construyeron una anécdota, basados en las informaciones de las entrevistas. También, en esta etapa los estudiantes demostraron todo lo aprendido con respecto a la estructura de un texto narrativo, sus elementos y características, al construir personajes y ambientes fantásticos. Seguidamente, realizaron un "mural parlante" usando la técnica artística de la pintura. Luego, los estudiantes crearon su primer cuento. Por último, en esta fase de transferencia los estudiantes narraron sus producciones a través de la técnica artística y fílmica del filminuto.

\section{Fase de observación}

Esta fase estuvo presente durante toda la experiencia, dado que los investigadores se involucraron en la realidad de la investigación, relacionándose con sus actores y participando en sus procesos. Por ello, los investigadores realizaron una observación participante y recolectaron información a través de diferentes instrumentos y técnicas como el diario pedagógico, la encuesta y la entrevista. 


\section{Fase de reflexión}

En esta fase, la acción de los investigadores se basó en reflexionar constantemente sobre lo observado en cada etapa del proceso investigativo y llevar a cabo acciones para replantear las siguientes intervenciones. Los datos obtenidos se analizaron con la intención de descubrir las dimensiones del problema y para planear la futura acción colectiva.

De esta forma, los investigadores realizaron tabulaciones con variables que se iban descubriendo en el desarrollo de cada actividad y crearon asociaciones útiles, codificando la información recogida a través de instrumentos como el diario pedagógico para el análisis del impacto de la intervención pedagógica.

La investigación se desarrolló en una población de 216 niños y niñas de básica, del grado tercero y séptimo de una institución educativa oficial de la ciudad de Floridablanca (Santander, Colombia). Específicamente, un grupo de básica primaria de tercer grado, correspondiente al grupo 3-2; y un grupo de básica secundaria, séptimo grado, correspondiente al grupo 7-1.

Se usaron varios instrumentos para la recolección de datos. En primer lugar, se inició con la encuesta como estrategia para detectar los intereses de los estudiantes respecto al aprendizaje de la lectura. El propósito fue obtener información de los grupos sobre la lectura para poder diagnosticar la situación de los estudiantes frente a este aspecto. Por supuesto, la información que se obtuvo es válida solo para el período en que fue recolectada ya que, tanto las características como las opiniones, pueden variar con el tiempo.

Otro instrumento que se utilizó en esta investigación fue el diario pedagógico. Este es considerado como una herramienta de gran utilidad para los maestros, no solo como posibilidad de escritura ni como narración anecdótica de lo que sucede en la clase, sino también como elemento para la investigación. Así, para esta investigación, el diario pedagógico no se concentró solamente en los hechos, sino también desde su diseño y estructura permitió el abordaje de experiencias significativas para los investigadores. De esta forma, los investigadores pudieron recopilar todo lo observado en la elaboración de las actividades propuestas e ir codificando la información en las categorías de análisis durante el desarrollo de la investigación.

El tercer instrumento utilizado fue la bitácora de metacognición. La metacognición es el proceso contrario al aprendizaje, pues centra los resultados solo en los contenidos. El énfasis está en la metacognición que cada alumno logra. Esta metacognición permite al alumno ir más allá de los contenidos proporcionados, ya que le es posible construir su propio aprendizaje significativo e integrador. En este sentido, los investigadores diseñaron situaciones que permitieron al estudiante (después de cada actividad) tener un espacio de reflexión y autoevaluación frente al aprendizaje construido. Al respecto, el concepto de metacognición propuesto por Campirán (1997 y 2000) como un estado de conciencia epistémico en el cual la persona "se da cuenta". Así, la metacognición es consciente por naturaleza. Surge cuando dos procesos de pensamiento (sea sobre conocimientos, habilidades o actitudes) se entrelazan y se produce un elemento cognitivo (relación, comparación, integración) de dicho enlace.

En síntesis, la fase de reflexión se basó en la observación participante y en la recolección de datos, de acuerdo con las categorías de análisis establecidas y que surgieron o se complementaron durante el proceso investigativo. Estas categorías obedecieron a la lógica de la investigación y se orientaron a los objetivos planteados. Dichas categorías fueron: comprensión lectora, expresión artística, expresión comunicativa y pensamiento divergente.

\section{Resultados}

Los resultados obtenidos en la investigación fueron producto del ejercicio de triangulación, en el cual se analizaron las respuestas de la encuesta inicial; no se tomó como referente un simple dato cuantitativo, sino como búsqueda de información que diera cuenta de la población objeto de estudio y del problema de investigación. La encuesta aplicada se constituyó por 15 ítems y la finalidad fue determinar los intereses de los estudiantes y la importancia que tiene para la población en estudio la lectura y su comprensión. Los resultados dieron luces sobre la situación básica de los involucrados 
en la investigación. La población, uniendo los grados tercero y séptimo, suman 62 participantes y sobre este total se presentó el análisis.

Así mismo, se analizaron dos instrumentos que permitieron visualizar si las tesis planteadas desde el diagnóstico eran verdaderas, si la escuela realmente necesita redimensionar lo que hace en el fortalecimiento de la comprensión lectora y si la propuesta hecha desde esta investigación tuvo sentido para propiciar este proceso de fortalecimiento. En primer lugar, se analizaron las observaciones generales de cada una de las unidades didácticas teniendo en cuenta tres elementos: el concepto que se quería alcanzar en cada una de las actividades, lo observado en la mediación del arte, Ilamado en el informe elaboración artística y, finalmente, la puesta en escena como momento de síntesis (lo que permitió mostrar lo logrado en cada uno de los participantes, y, por lo tanto, en el grupo en general). Todos estos elementos se cruzaron y entrelazaron con lo observado de las categorías planteadas y lo presentando en el ejercicio de metacognición.

Ahora bien, el análisis de datos se realizó desde lo pretendido en cada uno de los objetivos específicos planteados en la formulación del problema. Así que para responder al objetivo 1 (diagnosticar el nivel de comprensión lectora de los estudiantes del grado tercero y séptimo del Instituto Gabriel García Márquez) se presentaron los resultados más significativos de la encuesta realizada a los estudiantes de tercero y séptimo grado. Mediante la encuesta se recopiló información valiosa sobre los intereses de los estudiantes: El 37,5 \% de los encuestados manifestaron que sí les gusta leer y el $49,5 \%$ dice que a veces, mientras que el $13 \%$ manifiesta no sentir gusto por la lectura.

Con estos resultados se pudo confirmar que la idea que se tiene de la apatía por la lectura en los estudiantes de hoy puede ser una disculpa para asegurar la mediocridad en la escuela, y dejar de lado el pensamiento crítico que se debe desarrollar con el acto de leer. Específicamente, mirando los resultados arrojados en la pregunta “¿te diviertes al leer?", un 41,5\% los estudiantes manifiestan que sí.

Hasta este punto es posible afirmar que la relación gusto y diversión son favorables para la investigación. Pero, se plantearon entonces las siguientes cuestiones: ¿está la escuela propiciando esa relación en el proceso lector que se realiza en ella? y ies un asunto de estrategias usadas en la escuela para hacer el trabajo de la lectura, lo que no está funcionando?

Con los datos obtenidos en los ítems 2 y 15 de la encuesta realizada, los investigadores se acercaron a la comprensión y explicación de las preguntas anteriormente formuladas. A la pregunta: "Cuando lees ipor qué lo haces?", el 89 \% respondió: "porque quiero aprender".

Vale la pena aclarar que este porcentaje fue solo de los estudiantes del grado séptimo, mientras que el 59 \% de primaria expresó que lo hacía por la exigencia de un docente. Es importante resaltar que la edad, en este caso, es un factor a tener en cuenta en el desarrollo de la autonomía, pero esto no significa que se tenga un lector autónomo. Aquí es importante observar lo que la escuela hace con la lectura, las estrategias que usa, las mediaciones en el momento de abordar un texto y los alcances que tienen todos estos elementos en el acto de leer $y$ comprender. Ahora bien, el ítem 15 de la encuesta formuló: "La actividad que más le realizan sus profesores para saber si usted comprende una lectura es:". Las respuestas en orden descendente fueron: talleres individuales o grupales $57 \%$; preguntas escritas $35 \%$; preguntas orales $21,5 \%$; y realización de dibujos $15 \%$ (porcentaje obtenido únicamente en el grado tercero primaria).

Se pudo reflexionar sobre el ejercicio de la lectura en la escuela y de qué forma la comprensión lectora se hace solo con el objetivo de la memorización de conceptos propios de cada asignatura y el alcance de metas académicas. Igualmente, fue claro que el uso de estrategias diferentes al taller de pregunta-respuesta son poco usadas en el proceso de comprensión lectora. De la obtención de estos resultados se pudo encontrar el sentido de la investigación y la necesidad de plantear una secuencia didáctica mediada por las artes.

Durante la planeación e implementación de la secuencia didáctica se logró obtener resultados significativos para analizar el proceso del fortalecimiento de la comprensión lectora en la población objeto de estudio. El segundo objetivo de la 
investigación trazó la puesta en funcionamiento de una secuencia didáctica para el fortalecimiento de la comprensión lectora en la población objeto de estudio; dicha secuencia estuvo conformada por cuatro unidades articuladas con sus respectivas actividades. Finalmente, en cada actividad se desarrolló un diario pedagógico que fue utilizado como el instrumento que recogió toda la observación general y de cada una de las categorías planteadas en el trabajo de investigación.

En la unidad didáctica número uno (sobre los textos narrativos, específicamente en la exploración de mitos y leyendas de la literatura precolombina, haciendo uso del teatro y la tradición oral) se pudo observar, en cuanto a lo conceptual, que los estudiantes desde sus pre-saberes fueron construyendo el concepto de mito, haciendo uso de la tradición oral y relatando mitos y leyendas. A la vez fueron estableciendo las diferencias entre cada uno de ellos. Expresiones como: "un mito es una historia sobre algo", "es algo parecido a un cuento", "un mito es la respuesta a algo que se pregunta", "un mito habla del sol y las estrellas" o "un mito dice el nacimiento de las cosas" permitieron validar los pre-saberes para la comprensión de los conceptos. Algunas de las respuestas fueron plasmadas por los estudiantes en los ejercicios metacognitivos denominados evaluarte. El siguiente es un ejemplo del ejercicio evaluarte utilizado, el cual permitió valorar la efectividad de la secuencia didáctica aplicada en el grado tercero:

El estudiante en el anterior evaluarte identificó el conocimiento que construyó y lo definió con sus propias palabras como: "la leyenda es el origen de algo".

Se logró observar también la capacidad de comparar las creencias de los indígenas con las propias al realizar comentarios como: "el sol y la luna fueron creados por Dios en la creación y no fueron niños como en la historia" y el "el fuego lo crearon los cavernícolas", haciendo así reconstrucciones de las narraciones con sus propias palabras. De igual forma, los estudiantes determinaron la importancia de los relatos para quienes los crearon y la relación de estos con la actualidad. Así se evidenció el alcance de la intención cognitiva: analizar la estructura narrativa de un mito y una leyenda.
De estos resultados se pudo afirmar que en cuanto la competencia lectora los estudiantes mostraron, al inicio de las actividades, un desempeño bajo en este proceso debido a la dificultad para recuperar información literal. El hecho de haber utilizado un video quizá hizo que este proceso fuese un poco más lento; porque es claro que, hacia el final de la parte de la elaboración del concepto, se evidencia un avance significativo en la conceptualización.

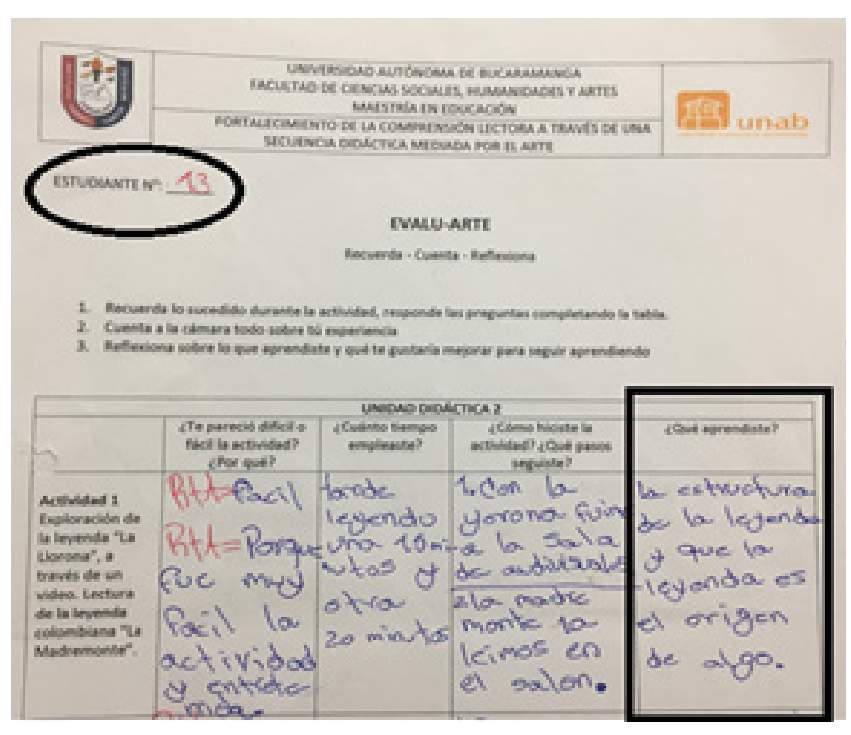

Figura 3. Formato evaluarte.

Fuente: elaboración propia basado en Campirán (2000).

Se pudo determinar que una vez los estudiantes avanzan a la elaboración artística se muestran más libres y sueltos para identificar las características de la tradición oral. De igual forma, a contrastar las diferencias que existen entre un mito y una leyenda teniendo en cuenta el tiempo, carácter, personajes y temas. Expresiones como "¿cómo era la vieja candela?", "¿qué figura hacemos más grande?", "¿cómo era el pelo de la vieja?", "¿la niña era bonita?", "¿qué es un tizón?", "¿cómo pintamos el tizón?" o “¿cuántos Nasa hacemos?" permiten afirmar que ya identifica fácilmente las ideas principales en los textos, esto indica que trabajan con estrategias de identificación y aproximación, además de tener desarrollada una competencia lingüística básica relacionada con la comprensión del texto.

También se pudo inferir que la mediación del arte hizo que los estudiantes dominaran el nivel de literalidad, expuesto por Rioseco-Izquierdo y 
Ziliani-Cárcamo (1994), los cuales describen a un lector que aprende información explícita y desarroIla destrezas de significación en palabras, oraciones y párrafos. La influencia de las artes en el ejercicio de comprensión hace posible que el contacto con el texto sea más cercano, placentero y comprometido; ya que la manipulación de material para crear productos artísticos de la propia autoría dispone a todos los sentidos. Además de representar actividades en las que los estudiantes ponen todo su empeño, primero, para comprender el texto y, segundo, para representar de la mejor forma esta comprensión que construyen con ahínco. Es posible confrontar la experiencia con autores como Cassirer (1973), quien asegura que el hombre es por naturaleza un animal simbólico, el cual se ha envuelto en formas lingüísticas, imágenes artísticas y símbolos míticos; esto facilita que la mente humana recree el mundo a través de su propio código simbólico. Así mismo, Chomsky (1995) hace referencia a la utilidad de las artes en la mejora de la comprensión lingüística; de acuerdo con el autor, es necesario entender, aceptar y poner en práctica el hecho de que las artes naturalmente son capaces de potenciar a la mente, predisponerla para el lenguaje y prepararla para la comprensión. El siguiente es un ejemplo de cómo a través del dibujo, la pintura y el teatro, los estudiantes Ilegaron a realizar obras artísticas de gran impacto:

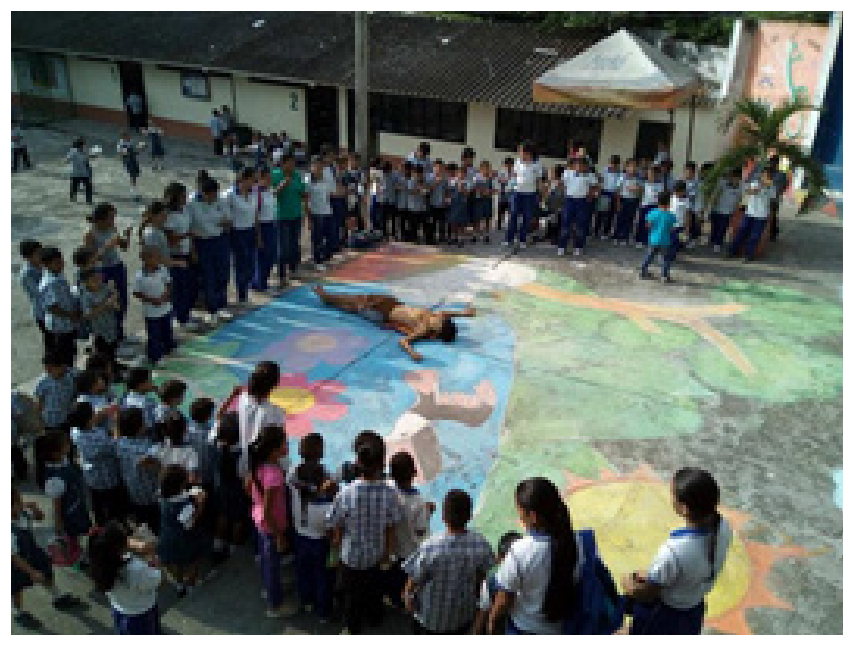

Figura 4. Escenificación y socialización de "Leyendas Bachillerato". Fuente: elaboración propia.

Al finalizar la actividad que se muestra antes, los estudiantes diligenciaron un evaluarte. Allí aparecieron comentarios como: "Aprendí a imaginar historias y crear personajes".

En la puesta en escena que se realizó en la unidad didáctica número uno se evidenció que se habían apropiado del personaje y entendían muy bien la temática que estaban presentando.

Se dividieron las responsabilidades o funciones para la escenificación de la siguiente manera:

- Narrador o narradores.

- Manipuladores de siluetas.

- Encargado de la proyección o luz.

- Encargado de presentar la narración.

También se vio claramente cómo hacían relaciones entre los elementos del tema con el contexto actual; inclusive manifestaban que sería bueno que las personas de hoy en día sintieran temor a los castigos y cambiaran sus vidas. Durante el desarrollo de la actividad se logró escuchar los siguientes comentarios de estudiantes durante la escenificación de los mitos: “¿Cuál personaje sigue?”, "Escuchemos el narrador", "Narra más despacio para poder sacar el personaje" y "Ya viene el final". Algunos estudiantes mostraron gran interés por comprender en su totalidad la historia con el fin de poder narrarla de forma apropiada. Los que tuvieron el papel de narrador fueron los estudiantes a quienes más se les observó interesados por comprender la totalidad del texto.

El identificar la estructura textual es una tarea relacionada con la competencia de "comprender la noción y propiedades del texto" que, a su vez, puede ser trabajada mediante la estrategia de organización, ya que el estudiante debe desarrollar la habilidad de organizar y reconocer el orden de la información obtenida, identificando las partes y relaciones entre ellas, así como la jerarquía entre los conceptos.

En la unidad didáctica número dos, que se centró en la narración de leyendas, se pudo observar que los estudiantes se mostraron interesados por el tema, así como los sonidos de llanto, espanto y miedo. Todos estos provocaron comentarios inmediatos como:" ¡Uy, qué miedo!", “iqué chimba!” o "¿qué será?". Se reconstruye la historia con todos los elementos recogidos con las apreciaciones y 
sentimientos vivenciados durante el relato. Seguidamente, se realizó la lectura individual de la leyenda colombiana La Madremonte. Se les observó atentos y todos terminaron el texto en pocos minutos (de 5 a 10 minutos).

Durante esta reconstrucción escrita, orientada por un formato, cada estudiante plasmó su comprensión e interpretación personal del texto. Algunos mostraron mayor destreza que otros para completar la guía. Algunos fácilmente dibujaron los tres momentos de la secuencia narrativa e incluyeron en sus composiciones su interpretación personal. Los estudiantes concluyeron que existe un constante entrecruzamiento entre el mito y la leyenda, donde se pueden encontrar explicaciones de carácter etiológico; es decir, que intentan explicar las costumbres y los ritos de una sociedad. Finalmente, hubo un momento en el cual los estudiantes socializaron sus composiciones por grupos y escogieron bajo sus propios criterios de selección las mejores. Para terminar la actividad, los estudiantes imaginaron y plasmaron en un formato la interpretación personal de la leyenda el Yurupary, o la imagen que más les Ilamó la atención, para ser plasmada en tiza sobre el asfalto. El siguiente es un ejemplo de la creación artística del grado tercero:

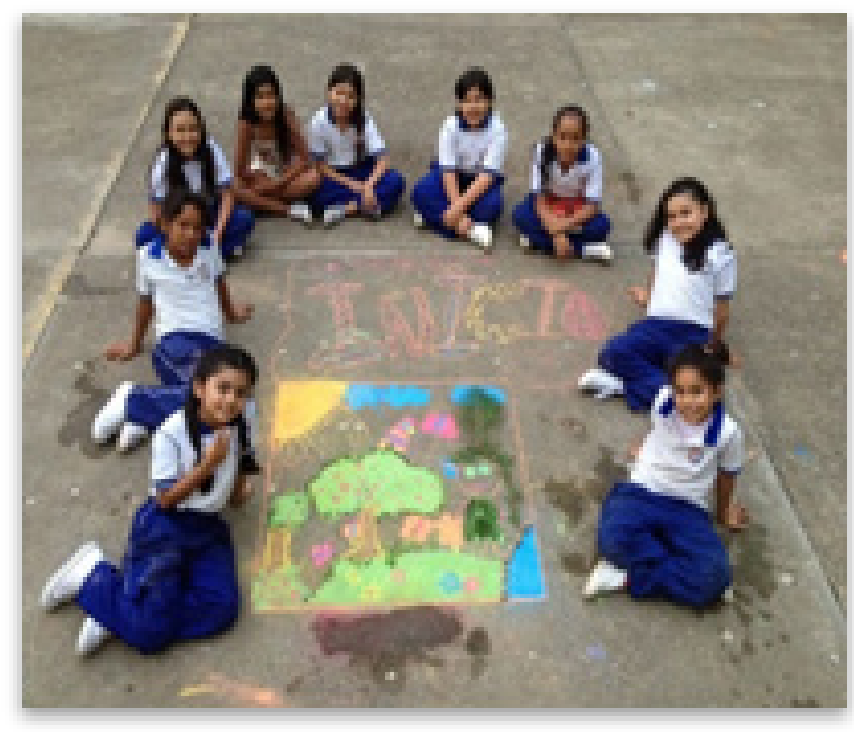

Figura 5. Pintura y narración de Leyendas Primaria.

Fuente: elaboración propia.

Durante la elaboración de los conceptos se notó una mejoría en los talleres realizados. Cuando se les propuso la lectura personal se les determinó buscar la información necesaria para hacer un dibujo dedicado a la Madremonte. El hecho de trazar objetivos de lectura apoya el proceso inferencial. El tener una meta posibilita que se haga una lectura enfocada a la comprensión de eso que se está buscando y se puedan relacionar los saberes previos con los conceptos que se abordan en las lecturas; ello aporta más elementos para que el estudiante comprenda lo que lee y pueda crear un nuevo pensamiento o complementar aquello que ya sabía. Predicción, inferencia y proposición se juntan en el proceso lector para posibilitar el acercamiento a la lectura de manera eficaz.

Smith afirma: "Si no podemos predecir, estamos confundidos. Si nuestra predicción falla, nos sentiremos sorprendidos. $Y$ si no tenemos nada que predecir porque no tenemos incertidumbre, estaremos aburridos" (1992, p. 80). Algunos estudiantes se atrevieron a realizar cambios al personaje, ampliaron los contextos en los que se desarrolla la historia. Expresiones como "le puse anteojos infrarrojos para que pudiera ver sus víctimas en la noche" $y$ "le hice las uñas alargadas como garras para que pudiera atrapar a sus víctimas" evidencian esto.

En el momento de la mediación artística se pudieron observar situaciones interesantes. Una es la relación dada entre color y sentimiento, era curioso oírlos expresar asuntos como "¿cuál color expresa maldad?" o "¿cuál color da más miedo?". Este tipo de interpretación permite subir el nivel de los procesos mentales y, desde allí, elaborar una comprensión mayor; además, permite la creación de otros mundos y visiones, lo que propicia el pensamiento divergente.

La transformación de la lectura, siguiendo a Goodman (citado en González-Gómez et al., 1992), y de acuerdo con los resultados obtenidos en el dibujo y la puesta en escena con la elaboración del gran dibujo hecho con tiza en el asfalto, muestra de la necesidad de inserción de las artes en el proceso educativo. Según el autor, es indispensable que los educadores tengan claro y ejecuten el compromiso de generar propuestas que respondan a la necesidad de compenetrar lo artístico con lo educativo en aras de la mejora continua de los fines de lo pedagógico 
y lo didáctico. En todo este proceso de la unidad didáctica se presentó (de nuevo) que el papel del narrador incentivó el interés en los estudiantes por comprender el texto. Así mismo, para la construcción artística los estudiantes expresaron todo su conocimiento acerca del texto.

Habiendo recorrido la mitad del camino (mediado por el arte) se puede afirmar que la estrategia es la adecuada, pues su enfoque es interactivo como el acto mismo de leer. Ya Popper (citado en Zubiría, 2004) había propuesto una serie de competencias cuya pretensión es precisamente el grado de contacto con la realidad; para ello se parte de la clasificación de esas realidades en tres mundos. Para el caso de esta investigación, la comprensión de textos mediada por las artes puede ser ubicada en el mundo número tres, al cual pertenecen las ideas y las creaciones culturales propias y exclusivas del ser humano como lo son las artes, las ciencias, la filosofía, el lenguaje, entre otras. Para este mundo, según el autor, las competencias construidas desde un enfoque netamente cultural y artístico son las más adecuadas para alcanzar la comprensión del mundo. Esta se convierte, entonces, en la tarea de la estrategia didáctica planteada: reajustarse a la realidad de los estudiantes y mejorar permanentemente las actividades que hacen uso del pretexto de las artes para alcanzar la comprensión de los textos y de la realidad.

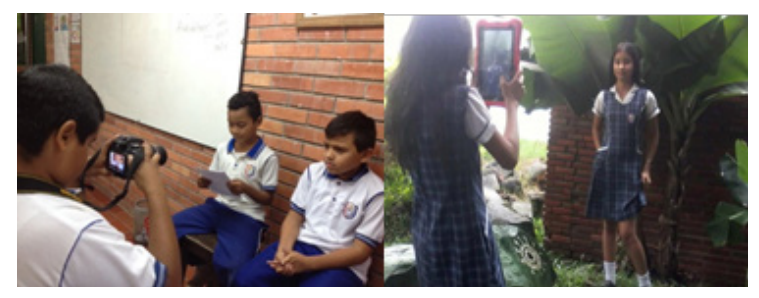

Figura 6. Entrevistas a primaria.

Fuente: elaboración propia.

La tercera unidad didáctica giró en torno a la elaboración de anécdotas para reconstruir su propia historia. El reto aquí fue mayor, pues se pretendió llegar a un nivel inferencial crítico en el nivel de la expresión artística. En el desarrollo de la actividad los estudiantes se mostraron muy ávidos y ansiosos tanto por la realización de la entrevista con el fin de conocer la vida de sus compañeros de clase como por el uso de herramientas tecnológicas (cámaras, celulares y tabletas) para recoger la información.

Las anteriores imágenes muestran cómo los estudiantes del grado tercero (izquierda) y los estudiantes del grado séptimo (derecha) realizaron la entrevista. Ellos siguieron las instrucciones dadas por el docente e hicieron buen uso de las herramientas tecnológicas; no se desviaron del fin, que consistía en grabar la entrevista. Algunos se mostraron más hábiles para el uso de la tecnología, para otros fue la primera experiencia y por lo mismo se les dificultó el uso. Tanto el entrevistador como el entrevistado se observaron nerviosos, pues manifestaron que nunca habían hecho una entrevista (menos aún que los entrevistaran y grabaran). Por este motivo sus palabras salieron entrecortadas y algo confusas. Sin embargo, hubo momentos de mucha alegría pues les causó risa lo que estaban haciendo, inclusive tuvieron que repetir las grabaciones. Finalmente, los estudiantes escribieron cada una de las respuestas (la mayoría recordaba buena parte); no obstante, todos escucharon por segunda vez la grabación de la entrevista.

Esta etapa del proceso la recuperación de información de la entrevista se realizó más rápido, con mayor precisión y la manejaban más fácilmente. Algunos, a partir de la entrevista, lograron sacar inferencias sobre las historias de vida de los otros. La fuerza del proceso estuvo en la estrategia artística de la fogata literaria, en la que se presentaron textos narrando anécdotas, bien estructurados e integrando muchos de los elementos propios de los textos narrativos.

Aquí puede decirse que la comprensión de lectura se presenta cuando los estudiantes logran establecer una relación directa con el texto (en este caso la entrevista) y con su posición frente a este. Siendo este el momento en el que se establece una relación con lo que se dice de manera literal en el texto y lo que piensan acerca del tema para generar un nuevo concepto (en este caso un texto narrativo de tipo anécdota); es decir, es el momento en el que hay una asimilación y una reflexión. En este ejercicio realizado en clases se presentó de manera general una relación por parte de los estudiantes de este tipo de comprensión. La siguiente imagen 
corresponde a la fogata literaria desarrollada por el grado séptimo:

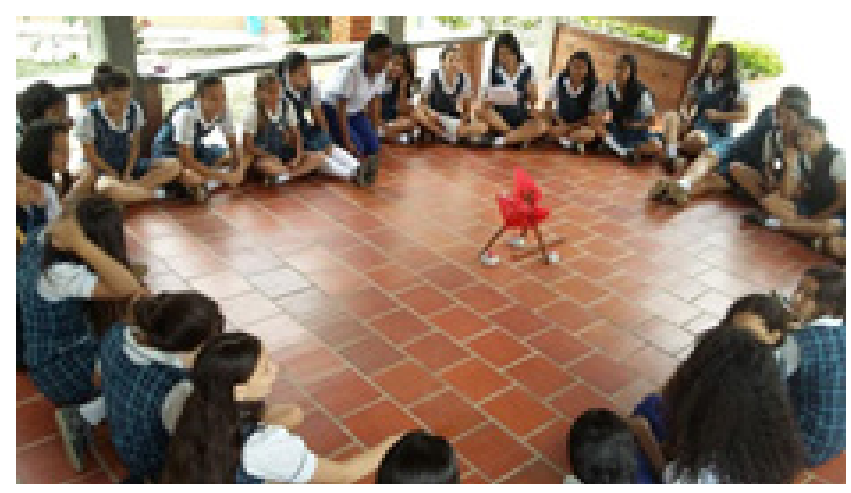

Figura 7. Fogata literaria grado séptimo.

Fuente: elaboración propia.

También es claro que la asimilación y el haber tenido la posibilidad de encontrar desde su interior elementos comunes con las historias de los demás posibilitó un elemento importante en el proceso de la comprensión lectora. Así lo exponen Carrasco y Baignol (2004): "El alumno aprende un contenido cualquiera - un concepto, un procedimiento, un valor- cuando es capaz de atribuirle un significado" (p. 63); por ello, no se puede esperar que haya comprensión cuando no existe una interiorización y una nueva manera de ver las cosas. El repetir de manera literal el contenido de un texto no implica que se haya comprendido; lo mismo ocurre cuando se reflexiona sin tener presente lo que se ha leído.

La última unidad didáctica se relacionó con el cuento. El objetivo fue construir un cuento fantástico utilizando las producciones artísticas del mural parlante (la cual fue la estrategia artística planteada); esta consiste en expresarse creativamente mediante la pintura. El desarrollo de la actividad fue exitoso; los estudiantes hicieron uso de sus pre-saberes, realizaron un mapa conceptual recordando la estructura y características del cuento. Seguidamente, cada uno realizó creativamente un boceto sobre el fondo, personaje u objeto que más les Ilamó la atención, para luego escribir un cuento. Se socializaron todas las imágenes, pero en común acuerdo se resolvió sacar las más representativas para unirlas, formando una sola, y poderla plasmar artísticamente en el mural parlante.
El desarrollo de esta actividad fue bastante fructífero para cada uno de los estudiantes, pues en el momento de la creación de su propia historia, teniendo como base el mural parlando, algunos de ellos ya tenían en sus mentes qué cuento inventar. Para, de esta manera, expresar el mensaje que le podía transmitir el mural parlante mediante la creación de su propia historia. Finalmente, todos participaron activamente, expresando sus intereses y emociones con respecto a la imagen realizada.

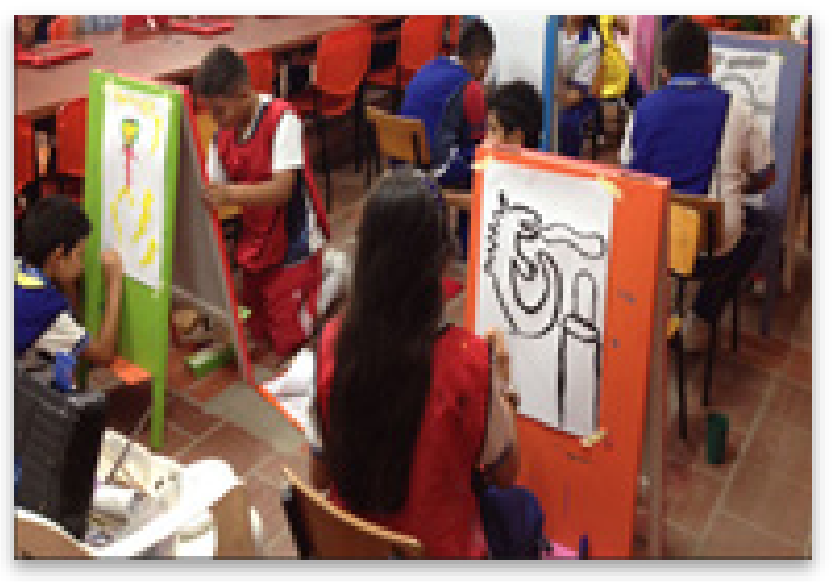

Figura 8. Elaboración de las imágenes del mural parlante por estudiantes del grado tercero.

Fuente: elaboración propia.

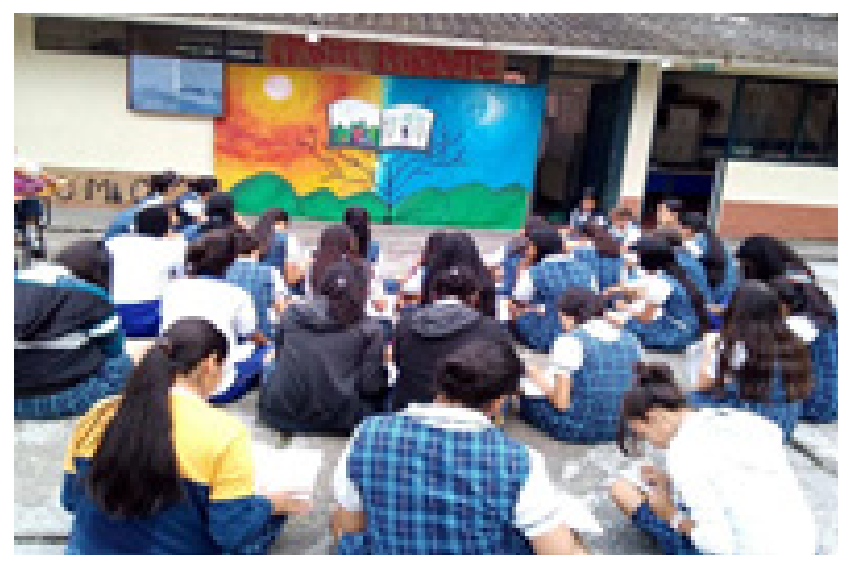

Figura 9. Narración del mural parlante por estudiantes del grado séptimo.

Fuente: elaboración propia. 


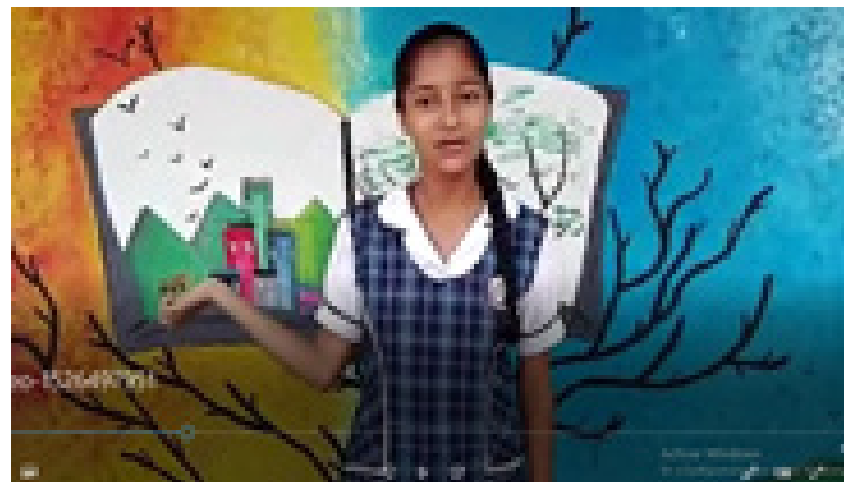

Figura 10. Imagen correspondiente a un filminuto desarrollado por el grado séptimo.

Fuente: elaboración propia.

Este conjunto de actividades se visualizó de manera satisfactoria para el proceso investigativo y la capacidad crítica de los estudiantes. Se dieron tres momentos importantes para la comprensión lectora. El primero fue el conocimiento del cuento como género narrativo, el segundo el espacio de la creación de personajes y escenas fantásticas que se convirtieron en el contexto donde se desarrollaría el cuento y el tercero el proceso de análisis y síntesis del cuento en cada uno. También hubo análisis en el momento en que se enfrentó a la narración en público y síntesis cuando, usando la técnica del filminuto, se pudo decir en un minuto el sentido del texto escrito. Estos niveles de comprensión lectora con todos los elementos se traducen en competencias y, en este sentido, Zabalza (2001), establece concretamente cinco clases de competencias que se adecuan a lo presenciado en esta estrategia. Estas competencias son:

- Las competencias de cognición, equiparables con las destrezas que adquieren los estudiantes en el uso de las habilidades de comprensión lectora por medio de las guías de trabajo diseñadas para este fin.

- Las competencias de rendimiento, que vendrían siendo aquellas habilidades adquiridas para demostrar su desempeño en el proceso de comprensión lectora.

- Las competencias de consecuencias, para el caso concreto de la estrategia estarían constituidas por el impacto de la misma sobre el desempeño lector de los estudiantes y sobre su misma realidad.

- Las competencias afectivas, que son el pilar de la estrategia didáctica, integradas por los gustos, sentimientos, preferencias y actitudes con las cuales los estudiantes entran en contacto con los textos.

- Las competencias de exploración, constituidas por las experiencias de los estudiantes en cada una de las actividades planteadas y que lograron conducirlos a un aprendizaje significativo. Este resulta muy valioso ya que se acercaron al proceso de comprensión lectora a través de su experiencia.

Un análisis concienzudo de estas competencias hace posible que la estrategia didáctica sea fortalecida, ya que permite identificar los elementos más fuertes para así proceder a enriquecerlos. Así mismo, facilita determinar los puntos débiles de la estrategia y encaminar todos los esfuerzos necesarios para convertir estos en fortalezas. Es de vital importancia hacer que las habilidades de comprensión lectora continúen siendo estimuladas a partir de las secuencias didácticas que combinan texto, técnicas artísticas y comunicación oral para facilitar la comprensión de las narraciones a las cuales acceden los estudiantes constantemente.

Es importante tener en cuenta que el docente que realmente desee que el estudiante construya su propio conocimiento debe persuadirle para Mina (2007), un estudiante que logre asumir el texto no como un simple documento de información, sino que logre asumirlo como un instrumento de conocimiento, aprenderá a descubrir lo mejor de la vida y abrir la mente al conocimiento y, sobre todo, abrir los ojos a la cultura de la humanidad

\section{Conclusiones}

De manera general, al finalizar el proceso investigativo (después de la fundamentación teórica, la búsqueda y análisis de la información), se pudo afirmar que para el contexto en el que se trabajó, y teniendo en cuenta que a pesar de que los procesos cognitivos se realizan de manera automática en la mayoría de las actividades que se realizan a diario, 
se requiere de una preparación para poder hacerlos de manera correcta.

En el proceso de la vida, al crecer es necesario aprender de los otros la manera como se hacen las cosas, desde el cómo lavarnos los dientes hasta cómo escribir. Por su parte, la escuela, los docentes tienen como labor enseñar a aprender, a conocer del mundo y de sí mismos para poder integrarse a la cultura en la que se vive y ejercer su papel como ciudadanos.

El hacer consciente el proceso cognitivo (cómo aprenden y saben lo que saben) aporta a los estudiantes una salida a la incertidumbre de si están o no haciendo bien las cosas. Para el caso de esta investigación, todo lo que tiene que ver con la lectura les abre un camino para que se autorregulen y aprendan a aprender por sí mismos. Esta les motiva pues, por lo general, no realizan las actividades de las asignaturas porque creen que no saben nada y de cierta manera temen a una calificación negativa. Es así como el docente no es el único a quién le corresponde esta tarea, sino también a los estudiantes para que pueden ver un cambio en su manera de comprender las cosas; lo que les permitiría la capacidad de autorregular sus procesos y hacer de la lectura una actividad agradable y sencilla.

Como conclusión general del trabajo investigativo se puede afirmar que la concepción de la lectura como un proceso compuesto por varias etapas (a las cuales el lector accede de forma gradual, utilizando para ello una serie de habilidades que, si son correctamente estimuladas, conducen a la compresión), el cual es el camino más adecuado y seguro para entrar en contacto con lo que se lee. Esto implica que leer no consiste solamente en descifrar códigos, sino, más bien, en construir un significado de los textos, atendiendo a elementos como lo son: las ideas propias, los conocimientos previos, los gustos, las expectativas, los sentimientos; en sí, el estilo único y particular de concebir la realidad en la cual el lector se encuentra inmerso.

Esta concepción, como lo ha expresado Colomer (2002), facilita que la lectura sea vista como una actividad agradable, enriquecedora y que aporta; sacándola de la visión tradicional de imposición, tedio y represión a través de la evaluación (visión que es muy común en el ambiente escolar). Por tanto, la comprensión de lo que se lee es la pretensión final del ejercicio lector. Existen diferentes niveles, como lo destacan Abusamra y Joanette (2012); y, para ello, es necesario entender en la escuela que la decodificación no sea el único objetivo de la lectura.

Por otro lado, el uso de la secuencia didáctica permitió desarrollar un trabajo preparado, ordenado y pensado en el alcance real de los objetivos formativos en los estudiantes. Por lo que es una alternativa metodológica de gran calidad que garantiza el diseño y ejecución de actividades pensadas en el aprendizaje de los estudiantes. Es importante mencionar que el desarrollo del trabajo planeado desde las secuencias didácticas trasciende las prácticas convencionales en las cuales los estudiantes son entes pasivos y receptores de datos. Se pasa a una labor significativa que hace partícipes a los estudiantes de la producción de conocimientos y desarrollo de habilidades. Además, con su implementación se tiene en cuenta que cada actor del proceso tenga claras las metas perseguidas $y$, por tanto, el sentido de las labores interrelacionadas en función de alcanzarlas.

Ahora bien, el contacto natural y agradable con los textos es el que facilita la comprensión de los mismos y debería ser el camino utilizado en todo momento por el lector. No obstante, como lo afirman Becerra y Charrría (2011), al llegar a la vida escolar a estos niños les es presentada una única forma de interpretar sus lecturas: la decodificación, coartando con ello la libertad que obligatoriamente debe existir en el contacto entre lector y texto; libertad que conduce a avanzar exitosamente por todas las etapas del proceso de comprensión.

La situación de si en la escuela se ha perdido la capacidad de afrontar la lectura para procurar el desarrollo de habilidades como la inferencia, la interpretación, la valoración y la creación, (generando así lectores incompletos, incapaces de entrar en contacto de forma natural y amena con los textos, de descifrar la pretensión del autor, de construir su propio significado de lo que lee, de crear a partir de los nuevos mundos que encuentra al interior de los textos, entre otras acciones), se deberá a la ausencia de estrategias que lleven a edificar un proceso 
de comprensión real que aporte a la construcción del conocimientos, así como de la cotidianidad, o será más un imaginario colectivo. En esta investigación se logró ver que es por la primera situación.

La propuesta del arte como mediador en el proceso de construcción de un camino hacia un pensamiento crítico, recorrido en los niveles de lectura presentados, comprobaron la tesis de Cassirer (1973) acerca de la facilidad de la mente humana para relacionarse con las imágenes y símbolos. Como fue posible evidenciar en el proceso de esta investigación, las creaciones artísticas modificaron la percepción que los estudiantes tenían acerca de la lectura, hicieron posible que estos entregaran todo su esfuerzo y dedicación no solo a elaborar producciones artísticas, sino a adentrase en el significado de los textos y construir una propia interpretación de los mismos. Cada técnica artística, combinada con las narraciones planteadas en las unidades didácticas, permitió la escenificación de las historias y la socialización de la comprensión que cada grupo de trabajo hizo

62 de estas. Con agrado, entusiasmo compromiso y sobre todo libertad, los estudiantes-lectores lograron alcanzar niveles complejos de comprensión; demostrando así que un pretexto para conectar al lector con el texto de forma natural, como el caso de las artes, es totalmente aplicable a nivel escolar e incluso fuera de este.

Así pues, estas representaciones a partir del dibujo, la pintura y el video lograron influir de manera positiva en el desarrollo de la inteligencia lingüística, visual-espacial y la creatividad del estudiante. Esto, siguiendo a Chomsky (1995), debido a que el estudiante explora su capacidad de comprensión, conceptualización y estímulo de invención y es capaz de crear nuevos significados en diferentes contextos, retroalimentando su construcción de conocimientos. Los trabajos artísticos presentan interpretaciones de las lecturas, representando de forma material el significado de los textos de manera indirecta, obedeciendo a una distinción mental más compleja que tiene ya conciencia de la semejanza y de la diferencia entre la cosa y la imagen. Así mismo, en algunos trabajos la representación visual está ligada a la imitación; es decir, el tratar de retener el contenido del texto y la intención de plasmar la idea principal del texto de manera literal. Pero no se trata de captarlo en su totalidad y de agotarlo en cierto modo, sino que destaca en él algunos rasgos característicos particulares para conferirles el sello de los rasgos artísticos propios de los estudiantes.

Por otra parte, el usar la metacognición como proceso coadyuvante para mejorar la comprensión de lectura en los estudiantes (al tener en cuenta los procesos de aprendizaje mentales y contextuales) permitió clarificar la manera como aprenden los estudiantes y abrió las puertas para mejorar tanto la práctica docente como la intervención en el aula de clase con los estudiantes; ya que el no considerar el grupo de personas con las que se trabaja impide que se cumpla con las meta de enseñar a los estudiantes a aprender. Cada grupo de estudiantes trae consigo particularidades sociales y culturales (edad, género, estrato socio-económico, entre otras) que determinan la manera de resolver las dificultades que sin duda se presentan en el aula de clase (conductuales y de aprendizaje), lo cual conlleva a pensar que cada grupo de personas con los que se trabaje debe ser considerado desde todos sus aspectos y necesidades. Así como en este caso las estrategias de indagación, de resaltado de ideas principales y elaboración de resúmenes favoreció la mejora de las dinámicas de lectura y de la clase, en otros contextos y grupos de personas se podrían requerir unas estrategias diferentes.

La aplicación de la estrategia didáctica de comprensión lectora a partir de las artes, así como su planeación y ejecución, es un proceso que requiere una buena disposición del grupo, libertad a la hora de leer y compromiso real para alcanzar la comprensión. Y fueron precisamente estos ingredientes los que se encontraron en la materialización de dicha estrategia y los que posibilitaron la obtención de resultados positivos de la misma. Las abstracciones visuales creadas por los estudiantes en sus representaciones a partir de las artes funcionan como operaciones mentales mediante las cuales una determinada propiedad del objeto o idea del texto se aísla conceptualmente a partir de una representación visual. Lo anterior genera un proceso que favorece ampliamente la comprensión lectora de los estudiantes con un tipo de inteligencia kinestésico (a través de sus trabajos artísticos en los que se usó la imagen, el trabajo grupal, el concepto 
visual, la manipulación directa de materiales, la expresividad y el color) que se hace evidente en todas sus dimensiones.

Una vez terminada y puesta en marcha la estrategia del arte como mediadora de la comprensión lectora en estudiantes de los grados tercero y séptimo del Instituto Gabriel García Márquez, se puede establecer una serie de conclusiones que podrían aportar a futuras investigaciones relacionadas con la expresión artística y el fortalecimiento del proceso lector.

Es importante el papel que desempeña el docente en su labor como mediador del proceso educativo y su capacidad para dominar un medio de expresión. La expresividad, en este caso el arte, contribuye a potenciar la creatividad y la atención; además, permite que el estudiante desde temprana edad estimule sus habilidades y capacidades kinestésicas. La finalidad de este estudio de investigación no fue formar artistas; en su lugar fue lograr que, por medio de la estrategia puesta en marcha, los estudiantes mejoraran y fortalecieran sus competencias para comprender diferentes tipos de textos y se motivase más a emplear la lectura en sus diversos niveles. Es decir, que el mundo narrado en los libros lo enlacen con conexiones de aprendizaje lúdico, corporal y expresivo.

En cuanto a la implementación de la estrategia se concluye que la misma puede ser usada en diferentes niveles de la educación básica; es decir, en primaria y secundaria. De modo que el docente puede, desde el arte, generar el aprendizaje de la lengua materna y de la comprensión lectora para fortalecer los componentes semántico, sintáctico y pragmático propuesto para el aprendizaje de la lengua casteIlana. El haber abordado en este estudio los grados tercero y séptimo permitió vislumbrar resultados positivos en dos niveles diferentes de la educación básica; y, en ambos casos, se pudo evidenciar el fortalecimiento del nivel literal e inferencial de lectura, así como el movimiento, el manejo del espacio, el desarrollo de la expresión oral y la motricidad.

También se pudo constatar la importancia del uso de diferentes recursos para la implementación de la estrategia por parte de los docentes, haciendo uso de su creatividad y de su saber pedagógico para generar el vestuario, recursos, música, instrumentos y demás insumos para desarrollar la estrategia. Aquí se vislumbra que la investigación deja las puertas abiertas para el estudio de toda una propuesta de elaboración de materiales escolares que faciliten los momentos de trabajo colectivo o para hacer del aula un espacio de expresión libre; donde la palabra, el gesto y el movimiento propicien la participación para despertar interés para actuar, plasmar y escuchar.

Este trabajo no pretendió presentarse como la panacea en la educación, pero sí como una experiencia pedagógica que permitió ver en los estudiantes un cambio en las habilidades comunicativas, afectivas y de desarrollo personal y social. Por lo tanto, este proceso investigativo se convirtió en un modelo para la institución, que replanteó el plan lector de la institución y logró enriquecerlo desde esta experiencia, la cual contó con estrategias dinamizadoras de aula y creación de didácticas que involucraron a los sujetos de aprendizaje desde las artes.

\section{Referencias}

Arnheim, R. (2015). Consideraciones sobre la educación artística. Paidós.

Abusamra, V. y Joanette, Y. (2012). Lectura, escritura y comprensión de textos: aspectos cognitivos de una habilidad cultural. Neuropsicología Latinoamericana, 4(1).

Campirán, A. (1997). El trasfondo filosófico. En Filosofía de la existencia. UV.

Campirán, A. (2000). Metacognición. En Habilidades de pensamiento crítico y creativo: transversalidad, vol. II. Colección Hiper-col. UV.

Carrasco, J. y Baignol, J. (2004). Técnicas y recursos para motivar a los alumnos. Rialp.

Cassirer, E. (1973). Lenguaje y mito. Ediciones Nueva Visión.

Centro Regional para el Fomento del Libro en América Latina y el Caribe, Organización de Estados Iberoamericanos (2004). Agenda de políticas públicas de lectura. Cerlalc

Chomsky, N. (1995). Reflexiones sobre el lenguaje (cap. II). Ed Sudamericana.

Colomer, T. (2002). El papel de la mediación en la formación de lectores. Lecturas sobre lecturas. 
Elliot, J. (2010). La investigación-acción en la educación. Morata.

González-Gómez, A., Charria de Gómez, M., Charria de Alonso, M. y Becerra-Cano, N. (1992). La escuela y la formación de lectores autónomos. Aique.

Latorre, A. (2003). La investigación-acción. Graó.

Mina, A. (2007). Aprende a pensar el texto como instrumento de conocimiento. Sánchez y Sierra.

Read, H. (1975). Imagen e idea. Fondo de Cultura Económica.

Rioseco-Izquierdo, R. y Ziliani-Cárcamo, M. (1994). Yo pienso, escribo y aprendo. Andrés Bello.
Ruiz, J. (2012). Metodología de la investigación cualitativa. Universidad de Deusto.

Smith, F. (1992). Comprensión de la lectura. Análisis psicolingüístico de la lectura y su aprendizaje. Trillas.

Tobón, S., Pimienta, J. y García, J. (2010). Secuencias Didácticas: aprendizaje y evaluación de competencias. Pearson-Prentice Hall.

Zabalza, M. A. (2001). Metodología docente. Revista de Docencia Universitaria, 9(3), 75-98. https://doi.org/10.4995/redu.2011.6150

Zubiría, M. (2004). Enfoques pedagógicos y didácticas contemporáneas. Fundación Internacional de Pedagogía conceptual Alberto Merani.

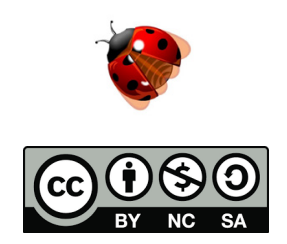

Esta obra está bajo licencia Creative Commons Atribución-NoComercial-Compartirlgual 4.0 Internacional 